\title{
Effectiveness of Family, Child and Family-Child Based Intervention on ADHD Symptoms in Iranian Students with ADHD
}

\author{
Mokhtar Malekpour ${ }^{1}$, Samira Hadi ${ }^{1} \&$ Sara Aghababaei ${ }^{1}$ \\ ${ }^{1}$ Department of Children with Special Needs, University of Isfahan, Isfahan, Iran \\ Correspondence: Sara Aghababaei, Department of Children with Special Needs, University of Isfahan, Isfahan, \\ Iran. E-mail: Sara.aghababaei@ymail.com
}

Received: November 26, 2014

Accepted: January 28, $2015 \quad$ Online Published: May 29, 2015

doi:10.5539/ijps.v7n2p31

URL: http://dx.doi.org/10.5539/ijps.v7n2p31

\begin{abstract}
The aim of the present study was to investigate and compare effectiveness of family, child, and family-child based intervention on the rate of ADHD symptoms in third grade students. The population for this study was all of students with ADHD diagnoses in the city of Isfahan, Iran. Multi-stage random sampling method was used to select subjects (60 children were included in this study). Children were randomly assigned into 4 groups, including 3 experimental and 1 control groups (each group consisted of 15 students). The children had been diagnosed by clinicians as having ADHD. In order to verify this diagnosis, Conner's parental rating scale was used at baseline to confirm that children had ADHD as well. The results indicated a significant difference between the 4 groups (In post-test). Results showed that family-child based intervention is the most effective method to decrease students' ADHD symptoms.
\end{abstract}

Keywords: attention deficit/hyperactivity disorder, effectiveness, family based intervention, child based intervention, family-child based intervention

\section{Introduction}

Attention deficit/hyperactivity disorder (ADHD) is a sustainable patterns of lack of attention, hyperactivity and impulsive behaviors which are more severe and prevalent than other children with similar developmental level. In order to diagnose ADHD, there are some symptoms which should be appearing before the age of seven; although most of the cases are diagnosed years after its appearance (Kaplan \& Sadock, 2000). Recently, the requirement of proven impairment before the age of 7 has been challenged and modifications to better address the issue in the upcoming Diagnostic and Statistical Manual of Mental Disorders (5th ed., DSM-V; American Psychiatric Association, 2000) criteria have been suggested (Bell, 2011). ADHD is one of the most common childhood neuro-developmental disorders, affecting 3 to 7 percent of school-aged children, with diagnosis more common in boys (5th ed., DSM-V; American Psychiatric Association, 2000; Polanczyk, De Lima, Horta, Biederman, \& Rohde, 2007).

The basic symptom domains of ADHD, as defined by the diagnostic classification systems, are hyperactivity, impulsivity, and inattention. Empirically, ADHD is not limited to the basic symptoms but can be associated with cognitive deficits (Frazier, Demaree, \& Youngstrom, 2004; Hervey, Epstein, \& Curry, 2004) and functional impairment in various life domains (e.g., Biederman et al., 1998, 2006). For example, ADHD is related to academic underachievement (Biederman et al., 2008; Roy-Byrne et al., 1997), and individuals with ADHD often have a history of school problems that cannot be explained by learning disabilities (Seidman, Biederman, Weber, Hatch, \& Faraone, 1998).

Every culture has children with ADHD (Barkley, Cook, \& Jr. Diamond, 2002). Ross (1987) found that classrooms in Thailand have comparatively fewer students with ADHD because children are expected and trained to behave and talk quietly in public in Thailand (Moon, 2011). Likewise, East Asian countries have lower rates of ADHD diagnosis, mainly due to their cultural background, Confucianism. East Asian societies highly value education, harmony with others, and loyalty to the country, parents, and elders. The cultural environment of East Asian countries contributes to having fewer students with ADHD and different concerns in the classroom setting when compared to US classrooms (Moon, 2011). In addition, there are some evidences suggesting that cultural factors may modulate the clinical manifestation of disruptive behavior disorders and ADHD (Livingston, 
1999; Reid, 1995). According to Batchelder (2003), social and cultural factors are keys to understanding trends in ADHD diagnosis and methylphenidate treatment (Moon, 2011).

Primary therapies emphasize on medication and behavior therapy (Chronis, Jones, \& Raggi, 2006). However, cognitive, behavioral-cognitive and neuro-cognitive interventions are being continued to be as other options for therapy (Barkley, 2006). In another category, these therapeutic approaches can be in the form of peers, classmates, school based, family based and child based interventions. Generally, helping these children who suffer from ADHD requires a comprehensive therapeutic method which is called a multi-pattern therapy which includes parents and child training, behavior management, usage of stimulant drugs, scheduling and suitable institutional supports (Behboudi, 2007).

Since behaviors of children with ADHD often damage parent-child relationship and increase stress among parents (Johnston \& Mash, 2001), a part of therapy would be the direct working with parents in order to modify their child rearing style in order to increase positive consequences for their children (Pelham, Wheeler, \& Chronis, 1998). Parent training is more common than other family interventions. Barkley (2001) points out parental need for behavior management in treatment of children with ADHD. According to Meta-analysis study carried out by Fabiano, Pelham, Coles and Gnary (2009), 174 studies where the effects of analyzed. Results indicated that behavior therapy is extensively effective in dealing with ADHD. Macford and Barlow (2004) did a qualitative study in which the effects of parents training were examined. The participants, who all were mothers, have reported an increase in their feeling of sufficiency, the decrease in psychic tension and increase in child obedience. Results from one study done by Hooshvar, Behnia, Khooshabi, Mirzaei and Rahgozar (2009) also suggested that parents' group training, concomitant with medication and occupational therapy programs, can play an outstanding role in decreasing harassing behavior problems, anxiety problems and hyperactivity. Hajebi, Hakim Shooshtari and Khajoddin (2005) found that teaching behavioral management to parents leads to the decrementof ADHD symptoms in their children.

In a Meta-analysis done by Farmer, Compton, Burns and Robertson (2002) the efficacy of family based intervention was investigated. The result showed that family based intervention decreased ADHD symptoms. Kazdin (2001) showed that family based and child based interventions has a good impact on decreasing ADHD symptoms.

With regard to the results of these studies, the aim of this study is to compare the efficacy of family based, child based and family-child based interventions on the rate of ADHD symptoms in third grade students'ADHD symptoms. Although, this research is repeated research but, it has been done in Iranian society, city of Isfahan (with more than two millions population). This research is done for the first time in Iran (city of Isfahan).

\section{Method}

The statistical population of this study included all 3rd grade elementary male students with ADHD in Isfahan city, Iran. Their age was 9 years old.

Samples: The sample of this study included 60 3rd grade elementary male Iranian students with ADHD. Multistage random cluster sampling method was used. In order to select subjects, of 6 educational areas of Isfahan city, in Iran, 2 areas were randomly selected. Then of these 2 areas 13 schools were randomly selected. Finally of these 13 schools, 60 male students with ADHD were randomly selected. These students were randomly assigned into 4 groups ( 3 experimental groups and 1 control group, each group included 15 students).

The following criteria were considered for samples in order to enter the research:

(1) No intellectual disability exist

(2) Having no specific and clear disorder except ADHD

(3) Parents' written consent for their children's participation

\subsection{Research Method}

The research method was experimental, with pre-test and post-test design. The authors first obtained permission for this study through bureau of education in city of Isfahan in Iran. After schools were randomly selected, from teachers were asked to identify students with ADHD symptoms according to the guidelines of DSM-IV-TR. To be assured about students who were identified by teachers as have ADHD, Conner's parental questionnaire (2001) was distributed among parents of these students (80 students).

In this way, 60 of them were identified having ADHD through this instrument. Then, 60 students with ADHD were assigned into 4 groups (each group with 15 students -3 experimental and 1 control groups). These 3 experimental groups included family based, child based and family-child based. Family based intervention 
according to Barkley program (Carr, 1999) and child based intervention including attention training, memory training, mind-body integration training and eye movement training (Moor \& Fallah, 2001) were administered on the experimental groups. Family-child based program was a combination of through trainings for other two groups as well. Indeed in this program family and child training was at the same time.

For experimental groups, 30 training sessions (10 sessions of child based intervention, 10 sessions of family based and 10 sessions of family-child based) were used (each session continued for 60 minutes). At the end of training sessions, Conner's parental questionnaire was again administered on experimental and control groups as posttest.

\subsection{Instruments}

In this research, Conner's rating scale was employed on parents in order to rate their children's ADHD symptoms. This scale was designed by Keith Conner (2001) and consists of 27 items. The scale is designed to measure the intensity of ADHD symptoms. Conner'sscale is one of the most well-known instruments for assessing of ADHD which is used in various researches.

Family based intervention, child based intervention, and family-child based intervention was used as independent variables.

\section{Results}

The results of ANCOVA analysis regarding the effect of child based, family based and family-child based interventions on the rate of ADHD symptoms have been presented in Table 2. In this analysis, the effect of pre-test was controlled. Descriptive data is presented in Table 1 as well.

Table 1. Mean and standard deviation scores of pre and post ADHD symptoms in experimental and control groupsposttest

\begin{tabular}{lllll}
\hline Group & mean & SD & mean & SD \\
\hline Child based & 44.80 & 3.23 & 39.86 & 2.77 \\
family based & 45.20 & 4.19 & 36.40 & 3.06 \\
Family-child based & 43.06 & 3.88 & 35.06 & 4.14 \\
Control & 45.40 & 2.64 & 46.46 & 4.29 \\
\hline
\end{tabular}

As Table 1 show, post test scores for ADHD symptoms have been decreased in experimental groups as well as control group.

Table 2. The results of ANCOVAwith respect to differences of four groups

\begin{tabular}{lllllll}
\hline Sources & df & Mean Square & F & Sig & Eta $^{2}$ & Observed Power \\
\hline Pretest & 1 & 48.02 & 3.82 & .5 & .06 & .48 \\
Group & 3 & 353.68 & 28.19 & .001 & .60 & 1 \\
Error & 55 & 12.54 & - & - & - & - \\
\hline
\end{tabular}

Results of Table 2 displays that there is a significant difference between child based, family based and family-child based interventions and control group in relation to ADHD symptoms ( $\mathrm{P} \leq 0.000)$. The amount of training effect is $60 \%$ and the observed power shows that the volume of sample was adequate.

Table 3. Tukey test, comparison of mean scores of ADHD symptoms in experimental and control groups

\begin{tabular}{llll}
\hline Group I & Group J & Mean Difference (I-J) & Sig \\
\hline Child based & family based & 3.46 & 0.05 \\
& family- child based & 4.80 & 0.01 \\
\hline
\end{tabular}




\begin{tabular}{llll}
\hline \multirow{3}{*}{ Family based } & Control & -6.60 & 0.01 \\
& Child based & -3.64 & 0.05 \\
Family- child based & family- child based & 1.33 & 0.74 \\
& Control & -10.06 & 0,01 \\
& Child based & -4.80 & 0.01 \\
Control & family based & -1.33 & 0.74 \\
& Control & -11.40 & 0.01 \\
& Child based & 6.60 & 0.01 \\
& family based & 10.06 & 0.01 \\
\hline
\end{tabular}

Results of Table 3 displays that there is a significant difference between family based, child based and family-child based interventions and control groups. Moreover, the results showed that among intervention methods, the most effective are the family based and family-child based intervention.

\section{Discussion}

The results of the study indicated that there is a significant difference between family based, child based and family-child based interventions among experimental groups and these experimental groups with control group as well. In other words, these interventionsin randomly assigned experimental groups as compared to control group decreased ADHD symptoms. The findings are consistent with studies of Macford and Barlow (2004), Mac-Mahon and Forhand (2003), Hooshvar et al. (2009), Hajebi et al. (2004), Farmer et al. (2002), Kazdin (2001), and Froelich et al. (2002). Moreover, the results of Tukey test showed that the most effective method was family-child based intervention. To explain the results of the present study it could be stated that the parents as the closest ones to the children play an important role in training and learning of children. Parents' training can decrease stress and tension of parents which leads to improvement of proper parent child relationship. This in turn leads to parents' understanding of their children's needs. Regarding the effectiveness of family-child based intervention, it seems clear that this type of intervention is significantly effective for parents who are still not ready to accept their children's problems. Since children are impressed by environment, especially by parents, therefore, parent training is an appropriate opportunity for parents to intervene their children's behavioral problems.

In summary, family-child based intervention, on one hand helps the child control, his behavior and on the other hand helps parents comprehend how to behave with their child. Therefore, both of these elements help improve child's ADHD symptoms. It is suggested that in future research, this comparison be done in other students with different grade levels.

\section{References}

American Psychiatric Association. (2000). Diagnostic and statistical manual for mental disorder (4th ed.). Washington, DC: Author.

Barkley, R. A. (2006). Attention-deficit hyperactivity disorder: A handbook for diagnosis and treatment (3rd ed.). New York: Guilford Press.

Barkley, R. A., Cook, E. H., \& Jr. Diamond, A. (2002). International consensus statement on ADHD. Clinical Child and Family Psychology Review, 5, 89-111. http://dx.doi.org/10.1023/A:1017494719205

Barkley, R. A., Edwards, G., Laneri, M., Fletcher, K., \& Metevia, L. (2001). The efficacy of problem-solving communication training alone, behavior management training alone, and the combination for parent-adolescent conflict in teenagers with ADHD and ODD. Journal of Consulting and Clinical Psychology, 69, 926-941. http://dx.doi.org/10.1037/0022-006X.69.6.926

Behboudi, H. (2007). Drug therapy for children and adolescents suffering from attention deficit hyperactivity disorder. Tehran: Special Disorders Education Publication, 74, 63-68.

Bell, A. S. (2011). A critical review of ADHD diagnostic criteria: What to address in the DSM-V. Journal of Attention Disorders, 15, 3-10. http://dx.doi.org/10.1177/1087054710365982. 
Biederman, J. et al. (2008). Educational and occupational under attainment in adults with attention-deficit/hyperactivity disorder: A controlled study. Journal of Clinical Psychiatry, 69, 1217-1222. http://dx.doi.org/10.4088/JCP.v69n0803

Biederman, J., Faraone, S. V., Spencer, T. J., Mick, E., Monuteaux, M. C., \& Aleardi, M. (2006). Functional impairments in adults with self-report of diagnosed ADHD: A controlled study of 1001 adults in the community. Journal of Clinical Psychiatry, 67, 524-540. http://dx.doi.org/10.4088/JCP.v67n0403

Biederman, J., Faraone, S. V., Taylor, A., Sienna, M., Williamson, S., \& Fine, C. (1998). Diagnostic continuity between child and adolescent ADHD: Findings from a longitudinal clinical sample. Journal of American Academy of Child and Adolescent Psychiatry, 37, 305-313. http://dx.doi.org/10.1097/ 00004583-199803000-00016

Carr, A. (1999). The Handbook of Child and Adolescent Clinical Psychology (1st ed.). New york: Routledge. http://dx.doi.org/10.4324/9780203360828

Chronis, A. M., Jones, H. A., \& Raggi, V. L. (2006). Evidence-based psychosocial treatments for children and adolescents with attention-deficit/hyperactivity disorder. Clinical Psychology Review, 26, 486-502. http://dx.doi.org/10.1016/j.cpr.2006.01.002

Conner, C. K. (2001). Conner's rating scale revised technical manual. New York: Multi health systems Incorporated.

Fabiano, G. A., Pelham, W., Coles, E., \& Gnary, E. M. (2009). A meta-analysis of behavioral treatments for attention-deficit/hyperactivity disorder. Journal of Clinical Psychology Review, 29, 129-140. http://dx.doi.org/10.1016/ j.cpr.2008.11.001

Farmer, E. M. Z., Compton, S. N., Burns, B. J., \& Robertson, E. (2002). Review of evidence base for treatment of childhood psychopathology externalizing disorders. Journal of consulting and clinical psychology, 70, 1267-1302. http://dx.doi.org/10.1037/0022-006X.70.6.1267

Frazier, T. W., Demaree, H. A., \& Youngstrom, E. A. (2004). Meta-analysis of intellectual and neuropsychological test performance in attention-deficit/hyperactivity disorder. Neuropsychology, 18, 543-555. http://dx.doi.org/10.1037/0894-4105.18.3.543

Froelich, J., Doepfner, M., \& Lehmkuhl, G. (2002). Effects of combined behavioral treatment with parent management training in ADHD. Behavioral and cognitive psychotherapy, 30, 111-125. http://dx.doi.org/10.1017/S1352465802001108

Hajebi, A., Hakim, S. M., \& Khajoddin, M. (2005). The effect of behavioral management education to preschool children suffering from attention deficit hyperactivity diorder. Iranian Journal of Psychiatry and Clinical Psychology, 84, 435-440.

Hervey, A. S., Epstein, J. N., \& Curry, J. F. (2004). Neuropsychology of adults with attention-deficit/hyperactivity disorder: A meta-analytic review. Neuropsychology, 18, 485-503. http://dx.doi.org/10.1037/0894-4105.18.3.485

Hooshvar, P., Behnia, F., Khooshabi, K., Mirzaei, H., \& Rahgozar, M. (2009). The effect of parents' group training on children with attention deficit-hyperactivity disorder. Journal of Rehabilitation, 10, 24-30.

Johnston, C., \& Mash, E. (2001). Families of children with attention-deficit/hyperactivity disorder: Review and recommendations for future research. Clinical Child and Family Psychology Review, 4, 183-207. http://dx.doi.org/10.1023/A:1017592030434

Kaplan, H., \& Sadock, B. (2007). Synopsis of psychiatry: Behavioral sciences/clinical psychiatry. Wolter Kluwer/Lippincott Williams \& Wilkins.

Kazdin, A. E. (2001). Bridging the enormous gaps of theory with therapy research, and practice. Journal of Clinical Child Psychology, 30, 59-66. http://dx.doi.org/10.1207/S15374424JCCP3001_7

Livingston, R. (1999). Cultural issues in diagnosis and treatment of ADHD. Journal of American Academy Child and Adolescence Psychiatry, 38, 1591-1594. http://dx.doi.org/10.1097/00004583-199912000-00021

McMahon, R. J., \& Forehand, R. L. (2003). Helping the noncompliant child: Family-based treatment for oppositional behavior (2nd ed.). New York, NY: Guildford Press.

Mockford, C., \& Barlow, J. (2004). Parenting programs: Some unintended consequences. Primary Health Care Research and Development, 5, 219-227. http://dx.doi.org/10.1191/1463423604pc200oa 
Moon, S. (2011). Cultural perspectives on attention deficit hyperactivity disorder: A comparison between Korea and the U.S. Journal of International Business and Cultural Studies, 6, 1-11.

Moor, T., \& Fallah, M. (2001). Control of eye movements and spatial attention. Neurology, 98, 1273-1276. http://dx.doi.org/10.1073/pnas.98.3.1273

Pelham,W. E., Wheeler, T., \& Chronis, A. (1998). Empirically supported psychosocial treatments for attention deficit hyperactivity disorder. Journal of Clinical Child Psychology, 27, 190-205. http://dx.doi.org/10.1207/ s15374424jccp2702_6

Polanczyk, G., De Lima, M., Horta, B. L., Biederman, J., \& Rohde, L. A. (2007). The worldwide prevalence of ADHD: A systematic review and meta regression analysis. The American Journal of Psychiatry, 16, 942-948. http://dx.doi.org/10.1176/ajp.2007.164.6.942

Reid, R. (1995). Assessment of ADHD with culturally different groups: The use of behavioral rating scales. School Psychology Review, 24, 537-560.

Roy-Byrne, P. et al. (1997). Adult attention-deficit hyperactivity disorder: Assessment guidelines based on clinical presentation to a specialty clinic. Comprehensive Psychiatry, 38, 133-140. http://dx.doi.org/ 10.1016/S0010-440X(97)90065-1

Seidman, L. J., Biederman, J., Weber, W., Hatch, M., \& Faraone, S. V. (1998). Neuropsychological function in adults with attention-deficit hyperactivity disorder. Biological Psychiatry, 44, 260-268. http://dx.doi.org/ 10.1016/S0006-3223(97)00392-2

\section{Copyrights}

Copyright for this article is retained by the author(s), with first publication rights granted to the journal.

This is an open-access article distributed under the terms and conditions of the Creative Commons Attribution license (http://creativecommons.org/licenses/by/3.0/). 